\title{
Stochastic Time series analysis of Runoff data of the Blue Nile at Eldeim, Sudan
}

\author{
Elsiddig Eldaw ${ }^{1,2, *}$, Tao Huang ${ }^{1}$, Adam Khalifa Mohammed $^{1,2}$, and Yahaya Muhama $^{3}$ \\ ${ }^{1}$ Faculty of Geoscience and Environmental Engineering, Southwest Jiaotong University, China. \\ ${ }^{2}$ Faculty of Water and Environmental Engineering, Sudan University of Science and Technology, Sudan \\ ${ }^{3}$ School of transportation and logistics engineering, Southwest Jiaotong University, China.
}

\begin{abstract}
To improve the management of operation system for the Roseires reservoir it is necessary to know the hydrological system of the Blue Nile river, which is the main water source of the reservoir. In this work, a Modified Thomas Fiering model for generating and forecasting monthly flow is used. The methodological procedure is applied on the data obtained at the gauging station of Eldeim in Blue Nile, Sudan. The study uses the monthly flows data for years 1965 to 2009 . After estimation the model parameters, the synthetic time series of monthly flows are simulated. The results revealed that the model maintained most of the basic statistical descriptive parameters of historical data. Also, the Modified Thomas Fiering model is applied to predict the values of the next fifty-five years, with excellent results that conserved most basic statistical characteristics of runoff historical series. The Modified Thomas Fiering model is able to realistically reconstruct and predict the annual data and shows promising statistical indices.
\end{abstract}

\section{Introduction}

In hydrology, time series models are often used for determining the design capacity of reservoirs [1]. Now, the climate change manifest clearly in the increases in average air and water bodies temperatures [2,3], snow melting and rising average sea level all over the globe [4]. The change in hydrological cycle leads to increased temperatures, evapotranspiration rates and intensities of rainfalls with the possibility of natural disasters [5]. These devastating effects requires the conduct of such studies, to predict the level of future effects and to develop the necessary measures that can ameliorate the situation.

Many researchers have attempted to handle the problem of data availability and identify the appropriate techniques to improve historical hydrological series data [6, 7]. The time series analysis of hydrology i.e., river flow data, in the statistical domain, is a broad area of specialization and has significant application in hydrological investigations [5]. During recent times, ecologists and hydrologists have been working on developing new methods of analyzing and managing changes in flow of river regimes [8-10]. The time series analysis is used for building mathematical models to compute statistics from river flow data using Thomas Fiering model. The main objective of this study is to apply and verify performance

*e-mail: siddigeldaw114@yahoo.com 
of time series model based on Modified Thomas Fiering for the monthly flow data of Blue Nile river at Eldeim gauging station.

Unfortunately, there are extremely limited time series modelling applications in the rivers in Sudan. Blue Nile is one of the rivers where limited attempts have been made to test applicability of time series models. The contribution of this paper is to generate and predict the monthly hydrological flow series using Modified Thomas Fiering model.

\section{Material and Method}

\subsection{Study area}

River Nile system in Sudan include the Blue Nile, White Nile and Atbara river. Most of the water in the Blue Nile basin has its sourced from the highland of Ethiopia (i.e., 2,000 - 3,000 $\mathrm{m}$ above mean sea level). This study considered the data of Eldeim monitoring station, one of the key monitoring stations of the Blue Nile, located in the south east of Sudan, very close to the Ethiopian boarder. The short rainfall period which spans from June to October, gives a high and concentrated runoff with maximum flow in August and September.

\subsection{Data Collection}

Mean daily runoff in Eldeim gauging station on Blue Nile, from the Ministry of Water Resources and Electricity of the Sudan from the period 01-January-1965 to 31-December-2009 were available. The monthly data used spanned from the period January 1965 to December 2009.

\subsection{Time Series Models}

\subsubsection{Modified Thomas Fiering (T-F) model}

Modified T-F model in its original form was adopted for the synthetic generation of monthly stream runoff data. After a brief analysis to historical record of Blue Nile river and estimation the behaviour of river, the transform of Thomas Fiering model was done by extracting the persistency from the river characteristics and the serial autocorrelation between the random residuals of the observed data. In this study, the Modified T-F model is based on the autoregressive approach [11] with application of Wilson Hilferty transformation of independent random number. This model presents a set of 12 regression equations and best represented by the following equation:

$$
Q_{i, j+1}=\bar{Q}_{j+1}+C_{j} \cdot\left(Q_{i, j}-\bar{Q}_{j}\right)+S_{j+1} \cdot \sqrt{1-r_{1, j}^{2}} \cdot \xi_{i, j+1}
$$

Where, $Q_{i, j+1}, Q_{i, j}$ are monthly flow in the $j^{\text {th }}$ month of the $i^{t h}$ year and i-step respectively, counting from the beginning of the generated series, $\bar{Q}_{j+1}, \bar{Q}_{j}$ are selective mean monthly flows in observed time series during the $\mathrm{j}+1$ and $\mathrm{j}$ month respectively, while $\mathrm{j}=1,2, \ldots \ldots, 12$ and $C_{j}$ is the regression line slope for the estimation of $\mathrm{j}+1$ month from the $\mathrm{j}$ month, $C_{j}$ is given by:

$$
C_{j}=r_{1, j} \frac{S_{j+1}}{S_{j}}
$$

Where, $S_{j+1}, S_{j}$ are variance of monthly values during $\mathrm{j}+1$ and $\mathrm{j}$ months from the data observed, $r_{1, j}$ is the lag-1 autocorrelation coefficient between the monthly flows and $\xi_{i, j+1}$ is 
Table 1: Basic statistical characteristics of synthetic monthly runoff time series for Eldeim station in Blue Nile River

\begin{tabular}{|c|c|c|c|c|c|c|c|c|c|c|c|c|}
\hline \multirow{2}{*}{ Statistical Property } & \multicolumn{12}{|c|}{ Months } \\
\hline & Jan & Feb & Mar & Apr & May & June & July & Aug & Sep & Oct & Nov & Dec \\
\hline $\bar{Q}$ & 8588.6 & 5439.1 & 4949.1 & 4900.1 & 7833.8 & 22384.9 & 83558.7 & 171021.3 & 124604.2 & 67850.2 & 27744.9 & 14294.2 \\
\hline $\mathrm{S}$ & 2379.2 & 1885.1 & 2329.2 & 2949.8 & 4466.9 & 9619.7 & 22269.5 & & & 22817.4 & 9005.1 & 38833 \\
\hline Max & 137 & 9483.7 & $120^{-}$ & 15690.4 & 233 & 51 & 144 & & 20 & 122 & 45724.3 & \\
\hline & 5 & 2301.0 & 15 & 12 & 229 & 9246.3 & 453 & 10 & 58 & 291 & 113 & 66 \\
\hline C.V & 28.01 & 35.05 & 47.59 & 60.88 & 57.67 & 43.46 & 26.95 & 19 & 23.49 & 34.01 & 32.82 & 27.47 \\
\hline Skewne & 0.27 & 0.51 & 1.1 & 1.55 & 1.43 & 1.49 & 0.52 & 0.23 & 0.42 & 0.94 & 0.53 & 0.37 \\
\hline Kurtosis & -0.68 & -0.68 & 0.61 & 2.65 & 2.1 & 2.1 & 0.11 & -0.29 & 0.6 & 0.37 & -0.71 & -0.76 \\
\hline
\end{tabular}

independent random variable with a normal distribution, zero mean and unit variance. The mean, variance and lag- 1 autocorrelation can be estimated from the given data set as follows

$$
\begin{gathered}
\bar{Q}_{j}=\frac{1}{n} \sum_{i=1}^{n} Q_{i, j} \\
S^{2}=\frac{1}{n} \sum_{i=1}^{n}\left(Q_{i, j}-\bar{Q}_{j}\right) \\
r_{1, j}=\frac{\sum_{i=1}^{n}\left[\left(Q_{i, j}-\bar{Q}_{j}\right)\left(Q_{i, j+1}-\bar{Q}_{j+1}\right)\right]}{n S_{j} S_{j+1}}
\end{gathered}
$$

The principle of calculations may be described by the following system. Consider the values of mean, standard deviation and lag-1 correlation, where $Q_{i, J a n}=\bar{Q}_{J a n}$ is defines the start of data generation. Then, the following equations are valid:

$$
Q_{1965, F e b}=\bar{Q}_{F e b}+r_{1, J a n} \frac{S_{F e b}}{S_{J a n}} \cdot\left(Q_{1965, J a n}-\bar{Q}_{J a n}\right)+S_{F e b} \cdot \sqrt{1-r_{1, J a n}^{2}} \cdot \xi_{1965, F e b}
$$

The value obtained from the Equation. $6\left(Q_{1965, F e b}\right)$ is applied to generate flow rate for the month of March i.e., $\left(Q_{1965, \text { Mar }}\right)$. Similarly, the estimated value for the month of December in the year under consideration $\left(Q_{1965, D e c}\right)$ can be used to generate the flow rate of January for next year $\left(Q_{1966, J a n}\right)$.

$$
Q_{1966, J a n}=\bar{Q}_{J a n}+r_{1, D e c} \frac{S_{J a n}}{S_{D e c}} \cdot\left(Q_{1965, D e c}-\bar{Q}_{D e c}\right)+S_{J a n} \cdot \sqrt{1-r_{1, D e c}^{2}} \cdot \xi_{1966, J a n}
$$

With the help of Excel random number generators tool, we obtained the $\xi$ values.

\section{Results and Discussion}

The salient basic statistical characteristics of the runoff historical time series of Eldeim gauging stations in Blue Nile river are given in Table 1.

To calibrate the Modified Thomas Fiering model, the monthly flows from Eldeim station for the period from 1.1965 to 12.2009 were used. It is necessary to estimate 36 parameters (12 means $\bar{Q}$, standard deviations S and Lag-1 autocorrelation coefficients $r_{1}$ ) and calculate the regression coefficient $C_{j}$ between the months as shown in Table 2.

After estimating the Modified Thomas Fiering model parameters, the series of historical monthly flows for 45 years were generated. These series were compared with the recorded monthly flows of Eldeim gauging station for the hydrological period of 45 years (1965-2009), 
Table 2: Estimated values of the Modified Thomas Fiering model parameters of Blue Nile, Eldeim station.

\begin{tabular}{|c|c|c|c|c|c|c|c|c|c|c|c|c|}
\hline \multirow{2}{*}{ Statistical Property } & \multicolumn{12}{|c|}{ Months } \\
\hline & Jan & Feb & Mar & Apr & May & June & July & Aug & Sep & Oct & Nov & Dec \\
\hline $\bar{Q}$ & 8588.6 & 5439.1 & 4949.1 & 4900.1 & 7833.8 & 22384.9 & 83558.7 & 171021.3 & 124604.2 & 67850.2 & 27744.9 & 14294.2 \\
\hline$S_{j}$ & 2379.2 & 1885.1 & 2329.2 & 2949.8 & 4466.9 & 9619.7 & 22269.5 & 33709.1 & 28945.6 & 22817.4 & 9005.1 & 3883.3 \\
\hline$r_{i, j}$ & 0.4742 & 0.6253 & 0.6897 & 0.7033 & 0.4401 & 0.4181 & 0.0760 & 0.0229 & -0.1461 & 0.0999 & 0.3302 & 0.4276 \\
\hline$C_{j}$ & 0.3724 & 0.7784 & 0.8738 & 1.0600 & 0.9476 & 0.9723 & 0.1211 & 0.0172 & -0.1182 & 0.0395 & 0.1423 & 0.2634 \\
\hline
\end{tabular}
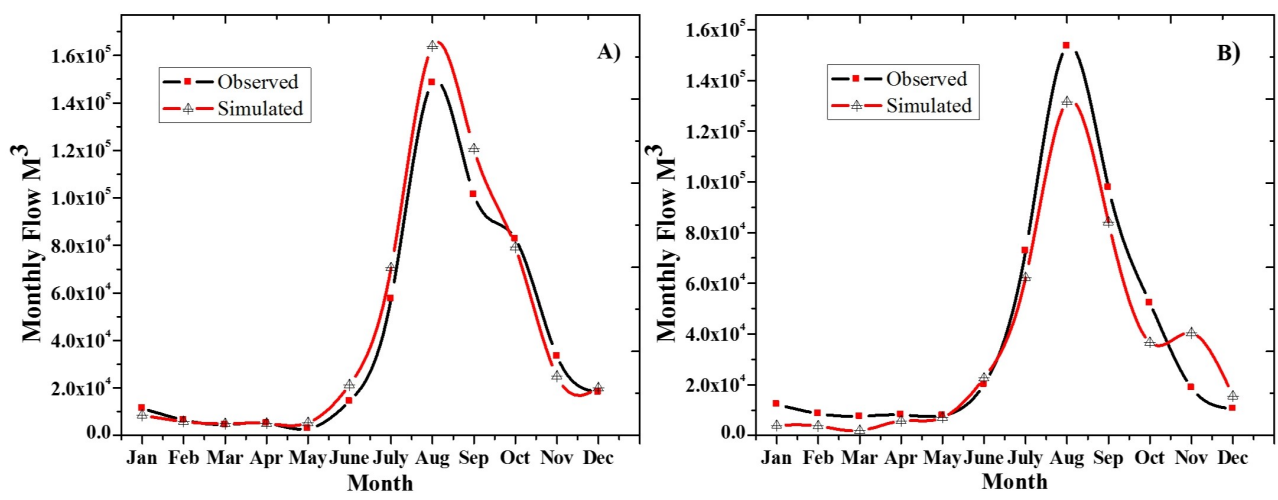

Figure 1: Comparison between observed and simulated monthly flows series of Blue Nile, Eldeim station for years (A) 1965 and (B) 2009.

using basic statistical characteristics like mean, standard deviation, maximum, minimum, Coefficient of Variation, skewness and Kurtosis in particular calendar months as shown in Table 3 and Figure. 2. For example, the Figures. (1A and 1B) represent the results of Modified Thomas Fiering model for observed and simulated monthly flows for the years 1965 and 2009, respectively.

To verify the performance of the Thomas Fiering model, the means, standard deviations, maximum, minimum and coefficient of variation of monthly flows in observed series is taken into account. From Table 3 and Figure. 2, it is observed that the means, standard deviations, maximum, minimum and coefficient of variation in the model's simulated monthly flows in all months better approximates the observed data. In general, skewness and kurtosis use to help initially understand general characteristics about the distribution data. In this study, the values of the skewness and kurtosis of the generated, predicted and historical data were compared. The model failed to well consider the long-term values of the coefficient of skewness and kurtosis for monthly flows in the simulated series. In other words, considerable difference was found between simulated and observed values for almost all the months.

Also, in this study, we applied the Modified Thomas Fiering model to forecast future values of flow rate. Table 4 and Figure. 3 demonstrate the results of basic descriptive statistic of the forecast value of Modified Thomas Fiering model for the next fifty-five years. The results obtained is related with observed data to justify the model's veracity. It is found that the basic statistical descriptive of historical flow series, except skewness and Kurtosis are not significantly distorted. The result therefore suggest that the Modified Thomas Fiering model is appropriate and can be applied to forecast monthly flow for planning, design and operation of hydrological infrastructure. 
Table 3: Representing the basic descriptive statistic of generated monthly runoff time series of Blue Nile, Eldeim station for 45 years

\begin{tabular}{|c|c|c|c|c|c|c|c|c|c|c|c|c|}
\hline \multirow{2}{*}{ Statistical Property } & \multicolumn{12}{|c|}{ Months } \\
\hline & Jan & Feb & Mar & Apr & May & June & July & Aug & Sep & Oct & Nov & Dec \\
\hline $\bar{Q}$ & 8123.1 & 5554.9 & 5292.8 & 5580.7 & 8305.8 & 22384.3 & 82302.3 & 174981.9 & 122945.0 & 71094.9 & 28667.1 & 14192.5 \\
\hline$S$ & 2452.7 & 1660.3 & 2463.2 & 2576.6 & 4022.5 & 9659.1 & 24055.8 & 36824.7 & 29884.9 & 21645.3 & 9895.9 & 3837.9 \\
\hline Max. & 14080.1 & 9096.9 & 10054.5 & 11207.7 & 15856.6 & 41389.1 & 136286.4 & 232422.0 & 175368.7 & 107193.6 & 43163.9 & 20945.2 \\
\hline Min. & 3095.7 & 1732.75 & 554.6 & 360.4 & 127.1 & 1617.5 & 42235.9 & 112375.7 & 74369.7 & 30545.0 & 12913.5 & 7136.7 \\
\hline C.V & 30.54 & 30.23 & 47.07 & 46.69 & 48.98 & 43.64 & 29.56 & 21.28 & 24.58 & 30.79 & 34.91 & 27.35 \\
\hline Skewness & 0.17 & -0.36 & -0.15 & -0.28 & -0.08 & -0.05 & 0.14 & -0.11 & 0.09 & -0.2 & -0.01 & 0.02 \\
\hline Kurtosis & -0.49 & 0.19 & -1.01 & 0.31 & -0.8 & -0.68 & -0.83 & -1.24 & -1.09 & -0.86 & -1.55 & -1.13 \\
\hline
\end{tabular}
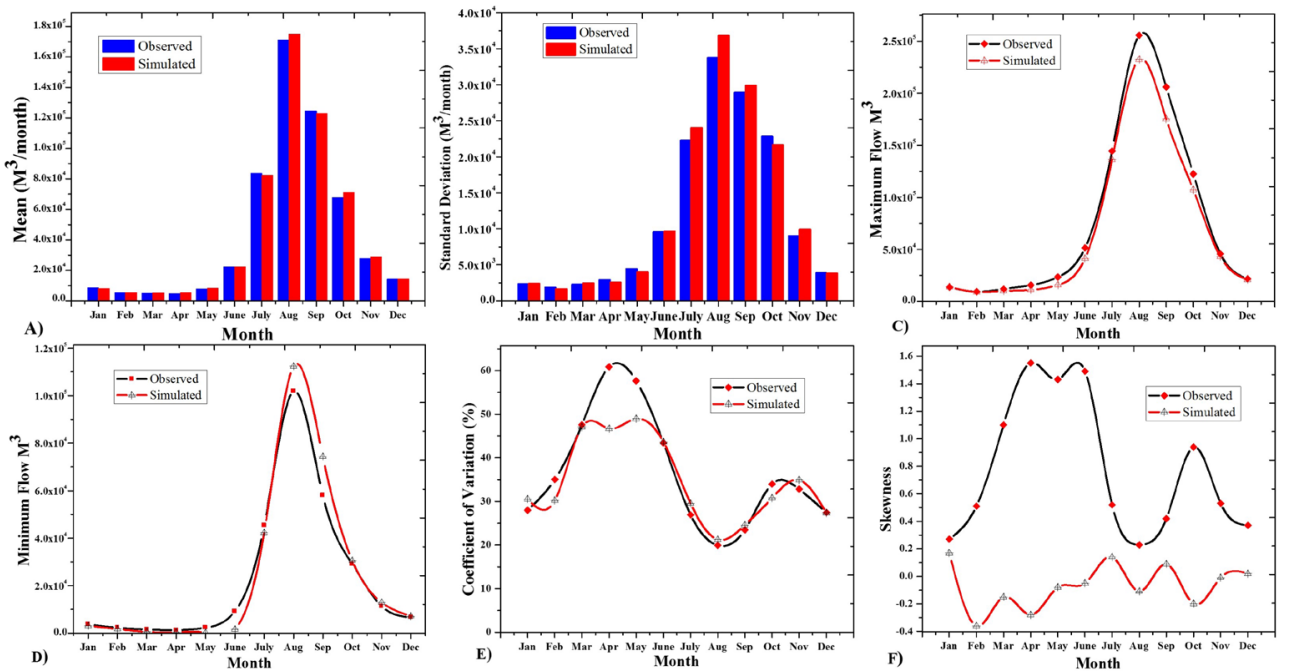

Figure 2: Long-term mean (A), standard deviation (B), maximum (C), minimum (D), coefficient of variation $(\mathrm{E})$ and skewness $(\mathrm{F})$ calculated for observed and simulated monthly flows time series of Blue Nile, Eldeim station.

Table 4: Representing the basic descriptive statistic of forecasts value for 55 years of Blue Nile, Eldeim station

\begin{tabular}{|c|c|c|c|c|c|c|c|c|c|c|c|c|}
\hline \multirow{2}{*}{ Statistical Property } & \multicolumn{12}{|c|}{ Months } \\
\hline & Jan & Feb & Mar & Apr & May & June & July & Aug & Sep & Oct & Nov & Dec \\
\hline $\bar{Q}$ & 8656.8 & 5263.6 & 4551.7 & 4173.0 & 7078.9 & 22734.5 & 83763.2 & 170377.2 & 128343.2 & 65834.8 & 27025.5 & 14517.2 \\
\hline $\mathrm{S}$ & 2308.8 & 1543.7 & 2455.1 & 2646.3 & 4509.4 & 9293.1 & 21608.6 & 33364.9 & 30394.8 & 22037.3 & 8765.7 & 3698.1 \\
\hline Max. & 13145.97 & 9454.27 & 9730.09 & 9812.2 & 14914.93 & 41185.47 & 131700.82 & 226251 & 172139.81 & 109834.22 & 43889.39 & 20430.06 \\
\hline Min. & 3594.5 & 2088.9 & 166.9 & 1476.6 & 4171.8 & 5661.5 & 47022.1 & 112504.3 & 76062.4 & 31681.3 & 12130.6 & 7937.0 \\
\hline C.V & 26.92 & 29.6 & 54.43 & 64.00 & 64.29 & 41.25 & 26.04 & 19.76 & 23.9 & 33.78 & 32.73 & 25.71 \\
\hline Skewnes & 0.09 & 0.08 & 0.15 & -0.18 & -0.2 & 0.19 & 0.24 & -0.07 & -0.25 & 0.38 & 0.22 & -0.28 \\
\hline Kurtosis & -0.75 & -0.13 & -0.68 & -0.54 & -0.49 & -0.87 & -0.91 & -1.26 & -1.39 & -0.9 & -1.14 & -1.22 \\
\hline
\end{tabular}



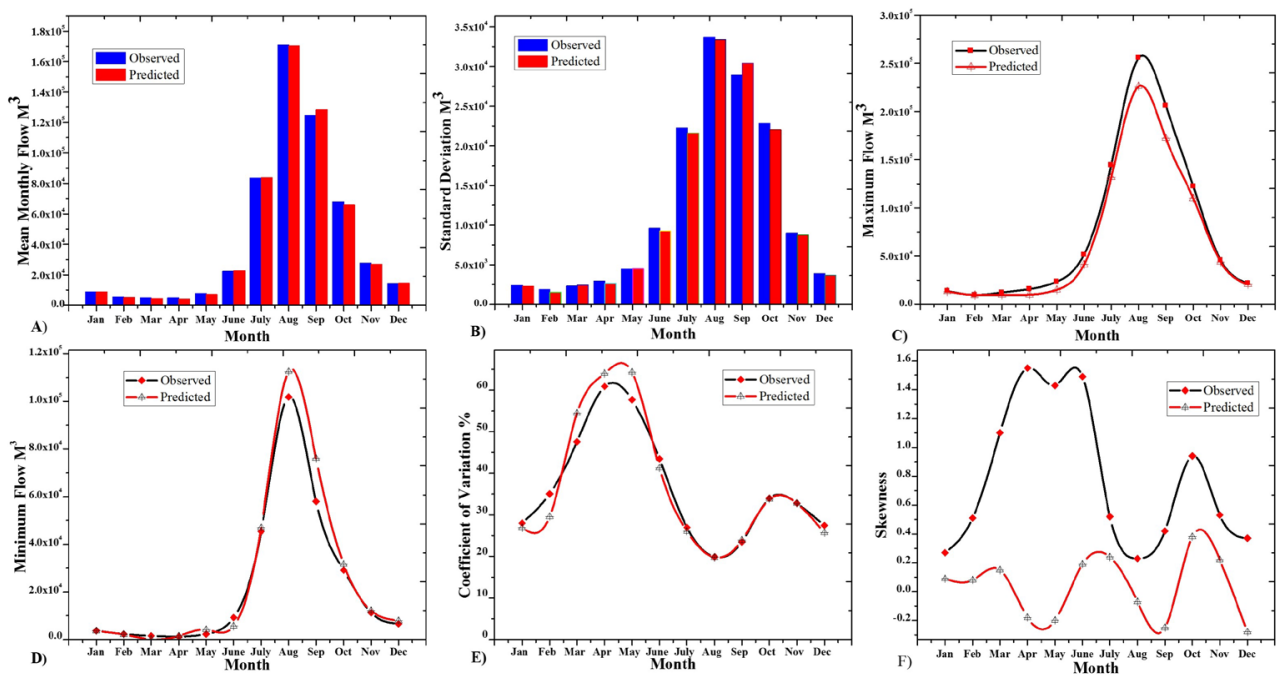

Figure 3: Comparison between observed and predicted of monthly flows series for (A) means, (B) standard deviations, (C) maximum, (D) Minimum, (E) coefficient of variation and (F) skewness in Blue Nile, Eldeim station.

\section{Conclusions}

In this study, the performance assessment for Modified Thomas Fiering model was carried out, using the monthly runoff data from Eldeim station on Blue Nile river, Sudan. The model was developed and applied to forecast the monthly inflow to Roseries reservoir, Sudan. The performance of the model was evaluated by comparing values of basic statistical descriptive parameters including mean, standard deviation, maximum, minimum, coefficient of variation, skewness and kurtosis between historical and simulated monthly data values. Thus, general results of predicting showed that, the Modified Thomas Fiering model can more accurately generate/forecast runoff data in Blue Nile river at Eldeim station. The model was applied to predict future values for the next 55 years. The prediction results were excellent and it maintained basic statistical characteristics of historical series.

\section{References}

1. Loucks, D.P., et al., Water resources systems planning and management: an introduction to methods, models and applications. (2005): Paris: UNESCO.

2. Razmi, A., S. Golian, and Z. Zahmatkesh, Non-stationary frequency analysis of extreme water level: application of annual maximum series and peak-over threshold approaches. Water resources management, (2017). 31(7): p. 2065-2083.

3. Choi, W., F. Pan, and C. Wu, Impacts of climate change and urban growth on the streamflow of the Milwaukee River (Wisconsin, USA). Regional Environmental Change, (2016). 17(3): p. 889-899.

4. Sathish, S. and S.K. Khadar Babu, Stochastic time series analysis of hydrology data for water resources. IOP Conference Series: Materials Science and Engineering, (2017). 263: p. 042140 .

5. R, C.H.L.a.R.A., Testing Hydrologic Time Series for Stationarity. JOURNAL OF HYDROLOGIC ENGINEERING, (2002). 7(2): p. 129 -136. 
6. Samaniego, L., A. Bardossy, and R. Kumar, Streamflow prediction in ungauged catchments using copula-based dissimilarity measures. Water Resources Research, (2010). 46(2).

7. Hunink, J., et al., Hydrological Modelling using Satellite-Based Crop Coefficients: A Comparison of Methods at the Basin Scale. Remote Sensing, (2017). 9(2): p. 174.

8. Richter, B., et al., How much water does a river need? Freshwater biology, (1997). 37(1): p. 231-249.

9. De Girolamo, A.M., et al., Simulating ecologically relevant hydrological indicators in a temporary river system. Agricultural Water Management, (2017). 180: p. 194-204.

10. Arthington, A.H., Environmental flows: saving rivers in the third millennium. Vol. 4. 2012: Univ of California Press.

11. Fiering, H.A.T.a.M.B., "Mathematical synthesis of stream flow sequences for the analysis of river basins by simulation, “ Design of Water Resources Systems, Chapter 12. Harvard University Press, Cambridge, Mass,. (1962). 